\title{
Understanding the Social Mobility Chances of Children from Working- Class Backgrounds in Britain: How Important are Cognitive Ability and Locus of Control?
}

Bastian A. Betthäuser* ${ }^{1,2}$, Mollie Bourne ${ }^{3}$, Erzsébet Bukodi ${ }^{1,2}$

ABSTRACT: Research in social stratification has shown that children from working-class backgrounds tend to obtain substantially lower levels of educational attainment and lower labour market positions than children from bigher social class backgrounds. However, we still know relatively little about the micro-level processes that account for this empirical regularity. Our study examines the roles of two individual-level characteristics—cognitive ability and locus of control -in mediating the effect of individuals' parental class background on their educational attainment and social class position in Britain. We find that cognitive ability mediates only about 35 per cent of the total parental class effect on educational attainment and only about 20 per cent of the total parental class effect on respondents' social class position, net of their educational attainment. These findings contradict existing claims that differences in the life chances of children from different social class backgrounds are largely due to differences in cognitive ability. Moreover, we find that although individuals' locus of control plays some role in mediating the parental class effect, its role is substantially smaller than the mediating role of cognitive ability. We measure individuals' social class positions at different points in their careers — at labour market entry and at occupational maturity — and find that the mediating roles of cognitive ability and locus of control are remarkably stable across individuals' working lives.

Key words: Intergenerational social mobility, Cognitive ability, Locus of Control, Inequality of opportunity, Social inequality, Educational inequality, Meritocracy, Social justice, 1970 British Cohort Study (BCS70)

Reference: Betthäuser, B.A., Bourne, M. and E. Bukodi (2020) Understanding the mobility chances of children from working-class backgrounds in Britain: How important are cognitive ability and locus of control? British Journal of Sociology. 2020, 1-17. https://doi.org/10.1111/1468-4446.12732

This paper is the pre-submission version of the published article. The published version can be accessed here: https://doi.org/10.1111/1468-4446.12732]

\footnotetext{
${ }^{1}$ Nuffield College, Oxford

2 Department of Social Policy and Intervention, University of Oxford

${ }^{3}$ Engineering UK, London

* Corresponding author: bastian.betthaeuser@nuffield.ox.ac.uk
} 


\section{Introduction}

Herrnstein and Murray's controversial volume The Bell Curve (1994) triggered a passionate debate over the role of cognitive ability in social inequality and its intergenerational transmission (see, e.g., Jacoby and Glauberman, 1995; Fischer et al., 1996; Devlin et al., 1997). More than 20 years later, this debate is still ongoing. In his recent volume Coming Apart (2010), Charles Murray argues that 'the reason that upper-middle-class children dominate the population of elite schools is that the parents of the upper-middle class now produce a disproportionate number of the smartest children" (2010: 60). Murray suggests that this further explains why individuals in advantaged labour market positions largely hail from higher social class backgrounds (2010: 46-68). He also posits that the transmission of intelligence is largely genetic and is reinforced by increasing homogamy, i.e. the growing tendency of people to form partnerships with individuals of similar social standing (ibid.). These views are echoed by a number of sociologists and social psychologists (see, e.g., Marks, 2014; Saunders, 2012, 1997; Gottfredson, 2003). With regards to the effect of individuals' social background on their educational attainment, for instance, Marks (2014: 88) argues that 'the inclusion of [cognitive] ability in the analysis reduces the impact of socioeconomic background considerably and in some cases to statistical insignificance". With respect to the effect of individuals' social background on occupational and economic outcomes, he further contends that 'the direct impact of socioeconomic background is even smaller, and smaller again after taking into account educational attainment and, to a lesser extent, cognitive ability" (Marks 2014: 234). Similar views also still hold traction within policy circles, as evidenced by a report by Dominic Cummings (2013: 74), the special advisor to then British Secretary of State for Education, Michael Gove, and chief special advisor to the Prime Minister, Boris Johnson. This report contends that "differences in educational achievement are not mainly because of "richer parents buying greater opportunity" and suggests that they are instead due to richer parents having more capable children than poorer parents. Cummings further argues that the successful pursuit of equal educational opportunity would therefore increase the effect of children's social background on their education achievement, thereby questioning the desirability of lowering the effect of children's social background on their educational attainment (ibid).

The views advanced in The Bell Curve and more recent iterations thereof have been called into question by evidence from different national contexts demonstrating that, whilst cognitive ability mediates part of the association between individuals' social backgrounds and their educational attainment, half or more of this association is mediated by factors other than cognitive ability (see Erikson, 2016; Mood et al., 2012, Bukodi et al., 2017; Hsin and Xie, 2016). ${ }^{1}$ Yet, while the extent to which cognitive ability mediates the association between parental class and individuals' educational attainment has now been widely investigated, we still know relatively little about (1) the role of cognitive ability in mediating the association between parental class and individuals' labour market positions, over and above its effect on educational attainment, and about (2) how the importance of cognitive ability compares to non-cognitive attributes in mediating the parental class effect both on educational attainment and labour market position. This paper aims to shed light on these issues.

There is reason to expect that the role of cognitive ability in mediating the parental class effect on individuals' labour market position is substantially smaller than its role in mediating the parental class effect on individuals' education. First, employers are likely to gauge applicants' 
cognitive ability mainly based on their educational credentials (Gottfredson, 1985), so that any differences in applicants' cognitive ability beyond the variation reflected in their level of education are unlikely to have a large effect on hiring decisions. Second, it has been shown that parents' social class position exerts a strong 'direct' effect on their children's labour market chances (e.g. Bernardi and Ballarino, 2016). However, it is possible that the mechanisms that account for this direct effect are not primarily related to individuals' cognitive ability, but relate to parents' social networks, which individuals can draw on during their job search (Erikson and Jonsson, 1998; Bernardi and Ballarino, 2016), as well as parents' economic resources, which can function as a financial safety net during individuals' transition into the labour market (Pfeffer and Hällsten, 2012). Given these direct effects of parental background on individuals' labour market position and the function of educational qualifications of signalling applicants' cognitive ability to employers, it can be expected that the role of cognitive ability in mediating the parental class effect on individuals' labour market position is smaller than its role in mediating the parental class effect on individuals' education.

If it was the case that - contrary to the claims made by Herrnstein and Murray (1994) and their more recent proponents - most of the effect of individuals' social background on their educational attainment and labour market position is not accounted for by individuals' cognitive ability, the question arises what other individual-level characteristics could account for this effect. Of relevance here is the emerging body of literature which highlights the role of non-cognitive attributes in shaping individuals' educational attainment and labour market positions (see, e.g., Jackson, 2006; Heckman et al., 2006; Cheng and Furnham, 2012; Hsin and Xie, 2016). This literature finds that it is individuals' locus of control, i.e. the extent to which people believe that they can influence the events and outcomes of their own lives, that is particularly strongly associated both with their social background and their educational and labour market outcomes. More specifically, there is evidence that parents' education and income, as well as parents' own locus of control, have significant effects on children's locus of control ( Ng-Knight and Schoon, 2017; Blanden et al., 2007; Gregg et al., 2008; Osborne Groves, 2005). In turn, individuals' locus of control has been shown to have a positive association with their educational choices, performance and overall attainment (Goodman and Gregg, 2010; Nelson and Mathia, 1995; Osborn and Milbank, 1987), the extensiveness of their job search (Caliendo et al., 2015; McGee, 2015), their income (Osborne Groves, 2005; Dunifon and Duncan, 1998; Feinstein, 2000), their later-life social class positions (Bukodi and Goldthorpe, 2019), and the amount of time they spend being unemployed or 'not in education, employment or training' (NEET) (MacMillan, 2013; Ng-Knight and Schoon, 2017).

The existing evidence that individuals' locus of control is associated with both their social background and a range of educational and labour market outcomes suggests that it may function as an important channel for the intergenerational transmission of inequality. Observing the constraints and hardships their parents face in daily life, children growing up in disadvantaged family environment may internalise a sense that their lives are primarily shaped by circumstances outside of their control—an 'external' locus of control—which may in turn adversely affect their education and labour market success. By contrast, children growing up in advantaged family environments may develop a sense that their lives and future are in their own hands-an 'internal' locus of control—which may in turn reinforce their likelihood of securing advantaged positions 
in the education system and the labour market. It has also been suggested that upper class parents actively seek to cultivate children's self-direction and internal locus of control, while working-class parents are less likely to encourage their children to challenge externally imposed conditions (Pearlin and Kohn, 1966). In sum, differences in the level of locus of control between individuals from disadvantaged and advantaged social class backgrounds may be accounting for a significant part of the differences in educational and labour market success between these groups.

Despite the existing research into the effects of locus of control on individuals' educational and labour market outcomes, we know relatively little about the extent to which locus of control mediates the association between parental background and individuals' educational and labour market positions. Blanden et al. (2007) find that locus of control does play some role in mediating the association between parents' and their children's income, but their study does not provide a precise estimate of the mediation per centage. By contrast, Stumm et al. (2009) find no evidence that locus of control mediates any of the association between the social class position of parents and that of their children, once children's education is accounted for. This result may be due to the fact that the analysis focuses only on individuals' probabilities of obtaining a position in the highest social class (the higher salariat). Consequently, the study may overlook a potentially more substantial role of locus of control with respect to mediating the parental class effect on whether or not people obtain a position in or above the lower end of the social class hierarchy-an outcome that is arguably of greater societal importance, given its known consequences for individuals' socioemotional wellbeing and physical health (see, e.g. Erikson and Torssander, 2008).

A further limitation of existing studies on the effects of both locus of control and cognitive ability on individuals' labour market positions is that they tend to observe individuals at only one point in time in their labour market careers. We consequently lack evidence on whether and how far the roles of cognitive ability and locus of control in mediating the parental class effect on individuals' social class positions change across their working lives. Yet, it is conceivable that cognitive ability and non-cognitive attributes come to play a more substantial mediating role later in individuals' careers. As noted above, the existing literature suggests that parents' social background exerts a substantial direct effect on their children's labour market success, with parents' professional networks aiding individuals in their job search and parental resources functioning as a financial safety net during the school-to-work transition. But these direct effects of individuals' parental class background can be expected to be mainly in operation at the time of labour market entry and are likely to weaken in later life, when individuals will have formed their own professional networks, become economically independent, and are generally more removed from the parental context. Hence, one may expect that, as far as individuals' parental background still exerts an effect on their labour market positions in later life, this effect is largely channelled via individuals' own characteristics, such as their cognitive ability and locus of control.

Our study seeks to contribute to the body of research on the roles of cognitive ability and locus of control in the intergenerational transmission of inequality by examining the extent to which variation in these characteristics can account for the tendency of individuals from workingclass backgrounds to obtain lower levels of educational attainment and less advantaged labour market positions than children from higher social class backgrounds. From a social justice perspective, understanding the educational and labour market chances of children who are born into families at the low end of the social class spectrum is of particular relevance, as they can be 
seen to be the most disadvantaged by the circumstances of their birth (Rawls, 1971). Given that individuals' social background is likely to affect their cognitive ability and locus of control mainly during their childhood (see Cunha and Heckman, 2009), and since one of our aims is to examine the importance of these attributes in mediating the association between individuals' parental class background and their educational attainment, we focus on individuals' cognitive ability and locus of control relatively early in life, measured at the age of ten. ${ }^{2}$ The two main research questions our study then seeks to address are the following. First, to what extent can individuals' cognitive ability and locus of control account for the effect of coming from a working-class rather than a more advantaged social-class background on (1) their educational attainment, and (2) their social class positions? Second, are there any changes in the mediating roles of cognitive ability and locus of control across individuals' labour market careers?

\section{Data and variables}

We use data from the 1970 British Cohort Study (BCS70), which follows the life courses of individuals born in one week in 1970 in Britain (University of London, Institute of Education, Centre for Longitudinal Studies, 2016). This dataset provides information on individuals' complete educational and labour market histories, their parents' occupations and social class positions, and their cognitive ability and locus of control in childhood. Most previous studies on educational and labour market inequalities in Britain restrict their analyses to cases with complete information and thus rely on the assumption that missingness in the data is completely at random (White et al., 2010). By contrast, we impute missing data points using multiple imputation by chained equations, which limits the risk of potential bias related to systematic item missingness in our data.

Table I. Ordinal educational scale and thresholds

1. No qualifications

2. Below O-level / NVQ 1 [sub-secondary]

3. 1-4 O-level passes / NVQ 2 [lower secondary - low perfromance]

4. 5+ O-level passes / 1 A-level pass / NVQ 3 [lower secondary-high perfromance]

Threshold 1

5. 2+ A-level passes [upper secondary]

Threshold 2

6. Tertiary-level sub-degree qualification / NVQ 4 [lower tertiary]

7. Teritary-level degree or higher degree / NVQ 5 or NVQ 6 [upper tertiary]

When examining the roles of cognitive ability and locus of control in mediating the parental class effect on educational attainment at labour market entry, we measure educational attainment by way of two binary threshold variables that are based on the seven-category, ordered scale of educational qualifications shown in Table I. This scale has been used extensively in previous 
research on educational inequality in Britain (for a detailed discussion, see Bukodi and Goldthorpe, 2013). The first threshold distinguishes between individuals who attained at least 2 A-levels or higher qualifications and those with lower educational qualifications. The second threshold distinguishes individuals with a tertiary qualification (sub-degree or degree-level qualification) from those without a tertiary qualification. We also account for individuals' vocational qualifications at the secondary and tertiary level, using the National Vocational Qualifications (NVQs) framework (see Wolf, 2011).

Table II. Social class cut-offs in NS-SEC

NS-SEC 1 and 2: Managerial and professional occupations

Cut-off 4

NS-SEC 3: Intermediate occupations

\section{Cut-off 3}

NS-SEC 4: Small employers and own-account workers

Cut-off 2

NS-SEC 5: Lower supervisory and technical occupations

Cut-off 1

NS-SEC 6 and 7: Routine and semi-routine occupations

Individuals' social class position is measured using a five-category, collapsed version of the sevencategory British National Statistics Socio-Economic Classification (NS-SEC) (see Rose and Pevalin, 2005: 38, Betthäuser et al., 2019). Based on this classification, we generate four binary dependent variables shown in Table II, that allow us to contrast different social class categories in a stepwise fashion. The first social class 'cut-off' identifies whether an individual obtained a position in the working class, i.e. in a routine or semi-routine occupation (NS-SEC 6 or 7) or in any of the more advantaged classes (NS-SEC 1-5). The second social class cut-off separates individuals in manual occupations (NS-SEC 5-7) from those in predominantly non-manual occupations (NS-SEC 1-4). In the British context, non-manual occupations are known to be regarded as granting a higher social status, as compared to manual occupations (Chan and Goldthorpe, 2004). Since the class category of small employers and own-account workers (NSSEC 4) in part also includes manual workers and since the nature of intergenerational transmission of inequalities is known to be different for the self-employed (Erikson and Goldthorpe, 1992), the third cut-off constitutes an alternative comparison whereby this category is combined with NSSEC 5-7 and compared to NS-SEC 1-3. Finally, the fourth cut-off identifies whether individuals obtain a position in the salariat, i.e. in a managerial or professional occupation (NS-SEC 1-2), or in any of the lower social classes (NS-SEC 3-7). Working with these four binary comparisons allows us to examine whether the roles of cognitive ability and locus of control in mediating the parental class effect on individuals' social class positions differs across the social class hierarchy. As noted above, we measure individuals' social class positions both at labour market entry and at occupational maturity. We define the point of labour market entry as the beginning of individuals' first employment spell that lasted six months or longer. Social class position at occupational 
maturity is measured at age 38, as it has been shown that individuals' social class position tends to stabilise after they reach their mid-thirties (see, e.g. Bukodi and Goldthorpe, 2011). In line with our focus on the life-chances of individuals from working-class backgrounds, we operationalise parental class using a binary measure comparing individuals from working-class backgrounds (NSSEC 6-7) with individuals from more advantaged social class backgrounds (NS-SEC 1-5).

We take what has now become the conventional approach to measuring cognitive ability by capturing the common variance across several indicators of individuals' verbal and non-verbal aptitudes (Colom et al., 2002; Deary, 2001). In the BCS70 these indicators are based on four subtests of the British Ability Scale that were administered to respondents at age ten. ${ }^{3}$ We carry out a principal component analysis, saving scores from the first component extracted. ${ }^{4}$ Our measure of locus of control is based on the 16-item CARALOC scale that was completed by respondents at age ten (Joshi, 2014; Gammage, 1975). We generate a continuous latent measure using the first principal component scores of the binary responses ('yes' or 'no') to these items. We z-standardise our measures of cognitive ability and locus of control. Tables AI and AII in the Online Appendix present the distributions of our dependent and independent variables, respectively. We control for respondents' gender in all our analyses, as well as for respondents' age, when individuals' social class position at labour market entry is the dependent variable. ${ }^{5}$

\section{Methods and Results}

As noted above, we seek to estimate the proportion of the effect of individuals' social background on their education and labour market positions that is mediated by their cognitive ability and locus of control, respectively. For this purpose, we first use linear probability models to estimate the path coefficients for the path diagram shown in Figure I. ${ }^{6}$ This conceptual model can be formally represented by the following linked regression equations:

$$
\begin{gathered}
x_{2}=\beta_{21} x_{1}+\varepsilon_{w} \\
x_{3}=\beta_{31} x_{1}+\varepsilon_{x} \\
x_{4}=\beta_{42} x_{2}+\beta_{43} x_{3}+\beta_{41} x_{1}+\varepsilon_{y} \\
x_{5}=\beta_{52} x_{2}+\beta_{53} x_{3}+\beta_{51} x_{1}+\varepsilon_{z}
\end{gathered}
$$

where $\beta$ represents the coefficient for each exogenous variable, with the first subscript referring to the dependent variable it is predicting and the second subscript referring to the exogenous variable in question. Error terms, represented by $\varepsilon$, are assumed to be stochastically independent. We divide the total effect of individuals' parental class background into two parts: the part that is mediated through cognitive ability or locus of control, respectively - i.e. the 'indirect' part, and the part that operates net of all paths through cognitive ability and locus of control - i.e. the 'direct' part. The former (indirect) part is computed as the product of the regression coefficients for the paths that link the relevant variables. By way of example, the total effect of individuals' parental class $\left(x_{1}\right)$ on their educational attainment $\left(x_{4}\right)$ is given by:

$$
\beta_{41}+\left(\beta_{42} * \beta_{21}\right)+\left(\beta_{43} * \beta_{31}\right)
$$


where $\beta_{41}$ quantifies the direct effect, $\left(\beta_{42} * \beta_{21}\right)$ quantifies the indirect effect via cognitive ability and $\left(\beta_{43} * \beta_{31}\right)$ quantifies the indirect effect via locus of control.

Figure I. Path model

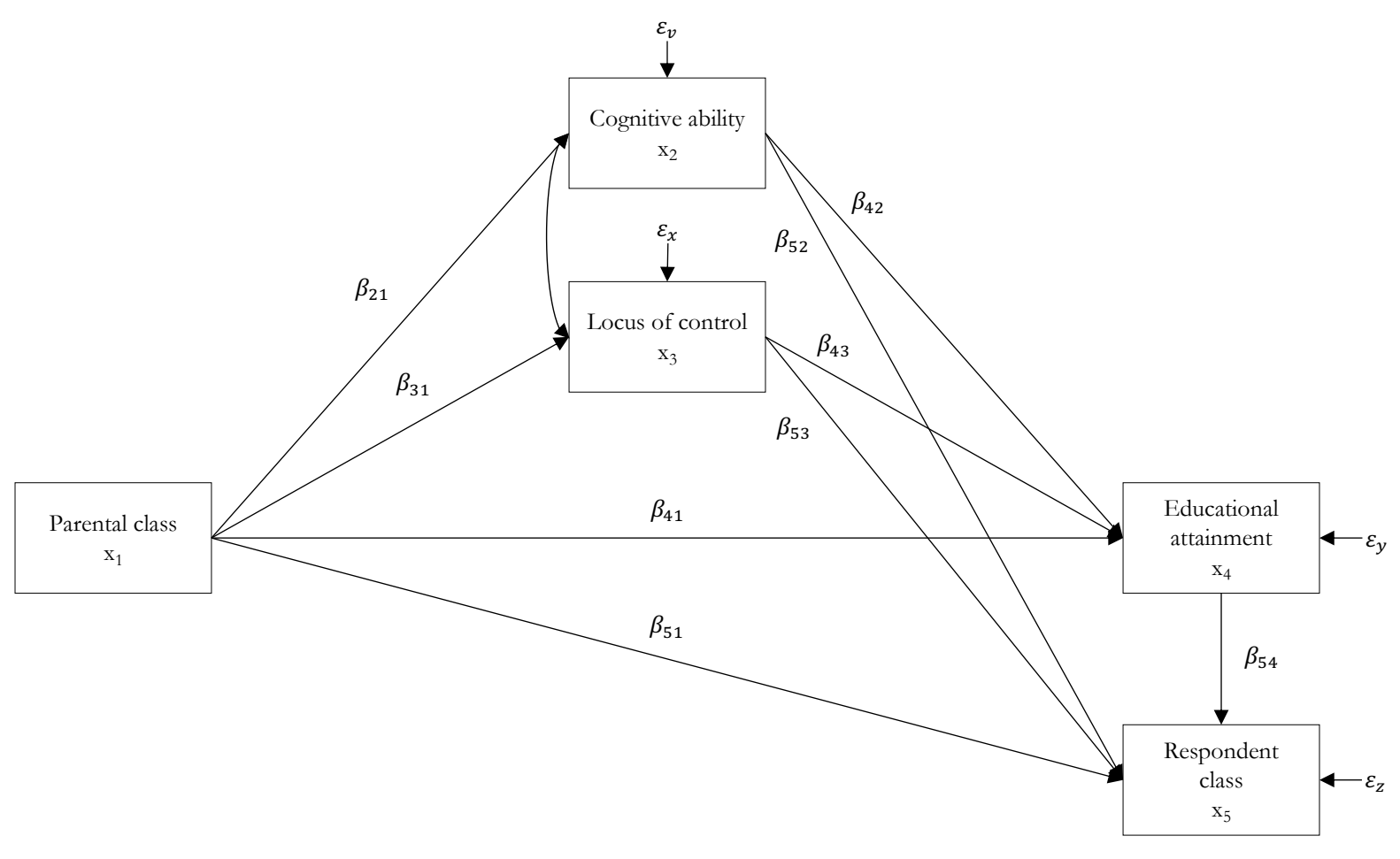

Using the path coefficients, we calculate the proportions of the parental class effect on individuals' educational attainment and social class positions that are mediated by their cognitive ability and locus of control. To continue with the example given above, the proportion of the total effect of parental class on educational attainment that is mediated by cognitive ability can be calculated by:

$$
\frac{\left(\beta_{42} * \beta_{21}\right)}{\beta_{41}+\left(\beta_{42} * \beta_{21}\right)+\left(\beta_{43} * \beta_{31}\right)}
$$

For our purposes, linear probability models in a path-analytical framework are preferable to binary logistic regressions, as differences in the unobserved heterogeneity across nested non-linear probability models may bias estimates of the mediation proportions we seek to estimate (see Karlson et al., 2012; Mood, 2010). Linear probability models have been shown to provide accurate estimates for models with binary outcomes provided that their distributions are non-extreme; i.e. with either response category containing between 20-80 per cent of the observations (see Cox and Wermuth, 1992). As shown in Table AI, this condition is met by all of our outcome variables. We also test the robustness of our findings using the alternative decomposition method developed by Karlson and colleagues (Karlson et al., 2012), which seeks to correct for the bias from unobserved 
heterogeneity across logistic regression models. Our results are robust across these two methodological approaches.

Table III shows the path coefficients we obtain using linear probability models to estimate the associations between individuals' parental class, cognitive ability, locus of control and our outcome variables. ${ }^{7}$ In line with our expectations, we find clear and statistically significant associations between individuals' parental class background and their cognitive ability and locus of control (see Table III, M1-2). However, the association between parental class and cognitive ability appears to be substantially stronger than the association between parental class and locus of control.

We also find significant effects of individuals' cognitive ability and locus of control on their educational attainment and on their social class positions at the time of labour market entry and occupational maturity, net of educational attainment. The effect of cognitive ability on educational attainment is much larger than the effect of locus of control (see Table III, M3-4). But the effects of cognitive ability and locus of control on individuals' social class position are more similar in magnitude (see Table III, M5-12). The fact that individuals' cognitive ability and locus of control are significantly associated with their parental class background, as well as with their educational attainment and social class positions suggests that these two characteristics play a role in channelling the intergenerational transmission of disadvantage. However, the coefficients for parental class shown in Table III, M3-12, also indicate that parental class exerts a statistically significant and substantial direct effect on individuals' educational and social class attainment that is not mediated by cognitive ability, locus of control or educational attainment.

Based on the path coefficients shown in Table III, we now calculate the proportions of the total effect of parental class on individuals' attainment that are mediated by cognitive ability and locus of control, and in the case of social class position, individuals' own education. Figure II plots the magnitude of the total parental class effect (black dots corresponding to right axis) on the likelihood of individuals to cross the two educational thresholds we examine, as well as the per centages of this total effect that is mediated by cognitive ability and locus of control (stacked bars corresponding to left axis). ${ }^{8}$

As one would expect, children from working class backgrounds are substantially—about 12 per centage points-less likely to obtain two or more A-Levels or a higher-level educational qualification, as compared to children from more advantaged social class backgrounds (see Table III, M3). Similarly, there is a substantial attainment gap between these two groups-about 9 per centage points - with regards to obtaining a degree (see Table III, M4). So far as the mediating role of cognitive ability is concerned, we find that it accounts for about 35 per cent of the effect of coming from a working-class background rather than from a more advantaged background on individuals' likelihood of crossing either of the two educational thresholds we consider (as illustrated by the grey bars). Our findings demonstrate that the role of cognitive ability in channelling the effect of coming from a working-class background on educational attainment is not dominant. While part of the difference in educational attainment between individuals from working-class backgrounds and individuals from higher social class backgrounds is due to the former having a lower mean level of cognitive ability at age ten, the large majority of the parental class effect on educational attainment-about 65 per cent-is not accounted for by individuals' cognitive ability. 
Table III. Path coefficients for path model (Figure I)

Dependent variables

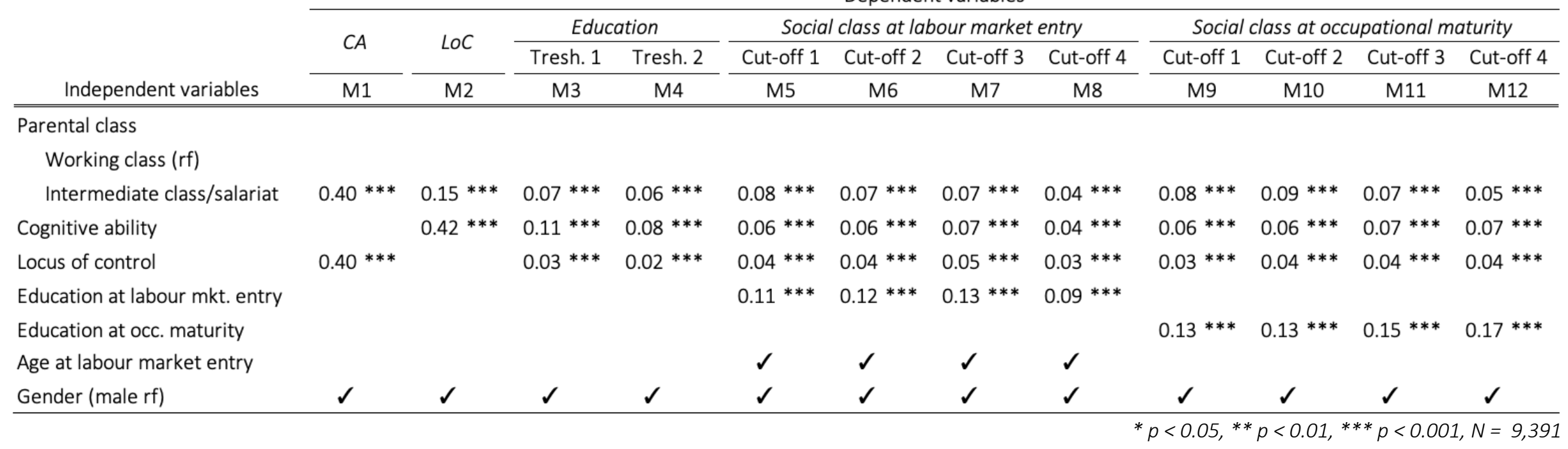


The role of locus of control in mediating the parental class effect on educational attainment is shown by the black bars in Figure II. As regards to both educational thresholds, we find that locus of control mediates only about 4 per cent of the parental class effect-a substantially smaller proportion than that mediated by cognitive ability. The path coefficients shown in Table III suggest that this difference results both from the weaker association between parental class and locus of control - as compared to the strength of association between parental class and cognitive ability - and from a weaker association between locus of control and educational attainment-as compared to the strength of association between cognitive ability and educational attainment.

Figure II. Decomposition of the total parental class effect on individuals' highest level of educational attainment at labour market entry

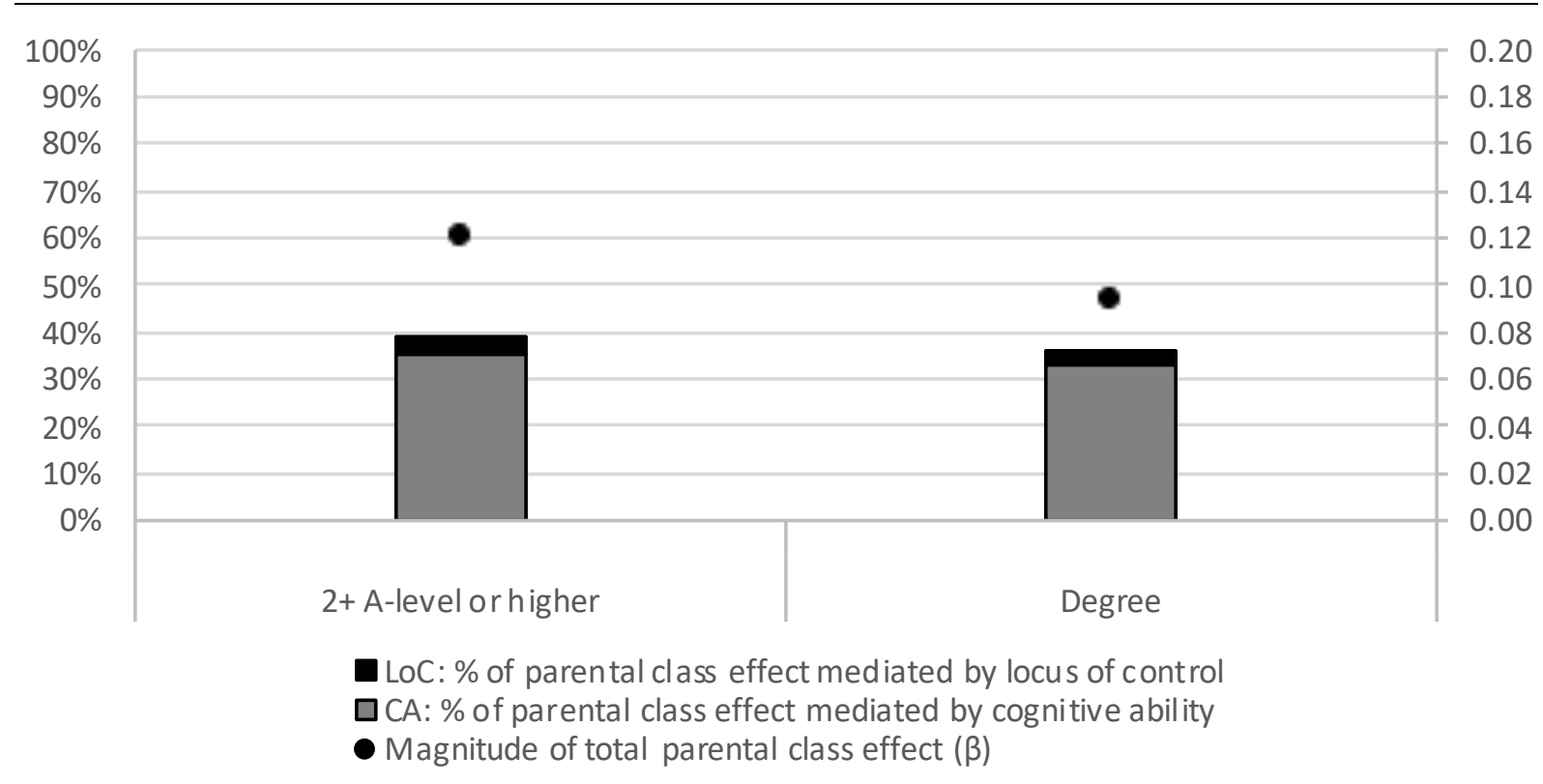

Notes: The total effect of parental class is marked by the black dots and the right axis ( $95 \% \mathrm{Cls})$. The per centage of the total effect that is mediated by cognitive ability and locus of control is marked by the stacked bars and the left axis.

Our finding that the role of locus of control in mediating the parental class effect on individuals' educational attainment is small not only in absolute terms but also when compared to the mediating role of cognitive ability may reflect the fact that one explicit function of educational qualifications is to assess individuals' cognitive ability; while individuals' locus of control may affect their educational attainment only indirectly, through study behaviour, motivations and aspirations. However, given the existing evidence that locus of control significantly affects individuals' labour market behaviour and outcomes (see, e.g., Caliendo et al., 2015; Ng-Knight and Schoon, 2017; Osborne Groves, 2005), one may expect locus of control to play a more important role in mediating the parental class effect on individuals' labour market position. Conversely, the role of cognitive ability in mediating the parental class effect on individuals' social class position may be expected to be smaller than with respect to educational attainment, given that employers are likely to gauge applicants' cognitive ability mainly based on their level of education (Gottfredson, 1985).

To investigate these issues, Figure III plots the total effect of parental class on individuals' social class position at labour market entry (see black dots corresponding to right axis), as well as the extent to which this total effect is mediated by individuals' highest level of education when 
they entered the labour market, their cognitive ability and their locus of control. For this step in our analysis, we use the standardised, seven-category measure of education, as discussed above. With respect to the size of the total effect of parental class, individuals from working-class backgrounds are about 14 per centage points more likely than individuals from more advantaged social class backgrounds to be found in the working class (as indicated by the black dot in the far left-panel of Figure III). The size of the attainment gap between children of the working class and children of more advantaged classes is roughly the same for the two subsequent social class 'cutoffs', whilst it is somewhat smaller (around 10 per centage points) for the likelihood of obtaining a position in the managerial and professional class.

Figure III. Decomposition of the total effect of parental class on individuals' social class attainment at labour market entry

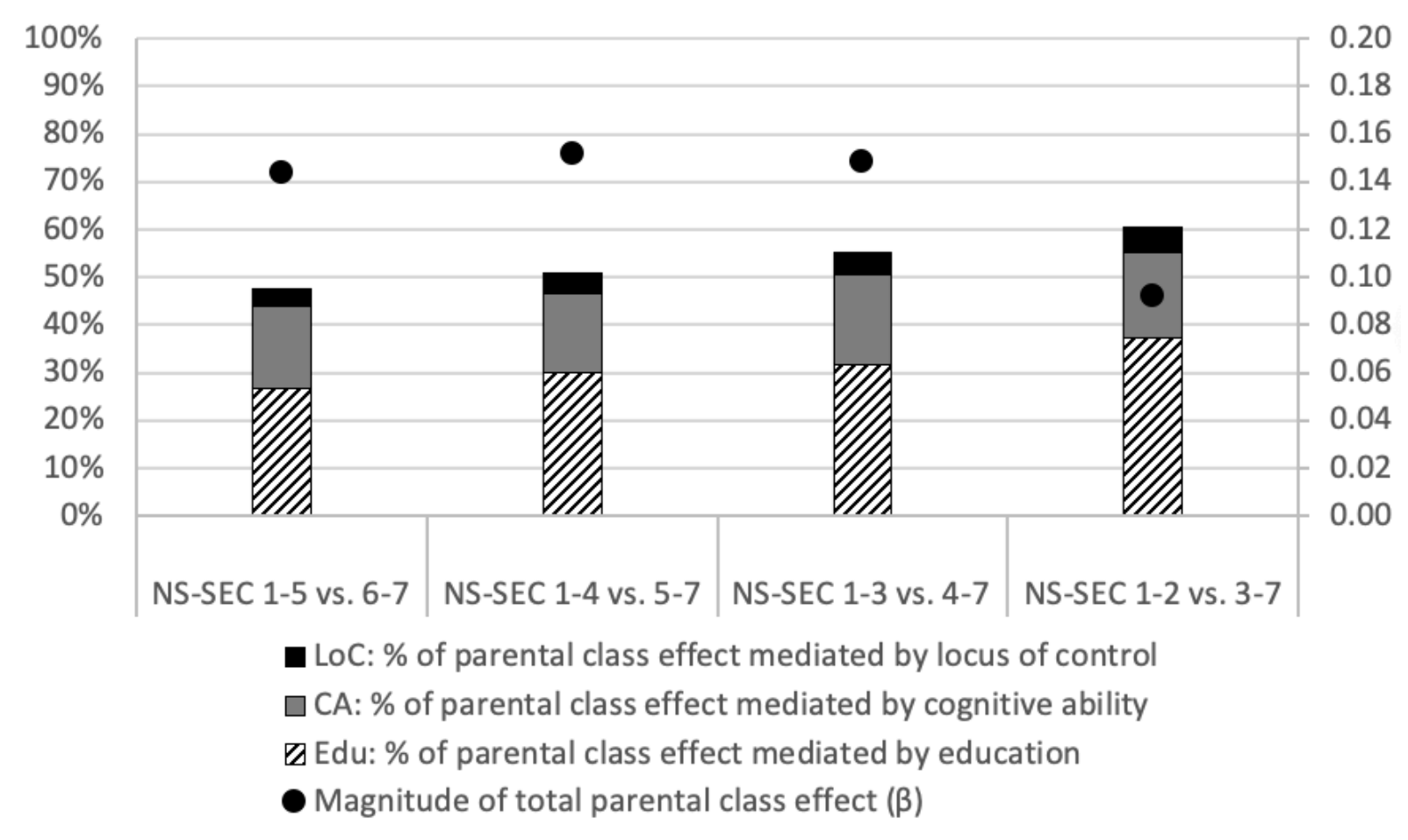

Notes: The total effect of parental class is marked by the black dots, which correspond to the right axis $(95 \% \mathrm{Cls})$. The per centage of the total effect that is mediated by educational attainment, cognitive ability and locus of control is marked by the stacked bars, which correspond to the left axis.

It is also apparent that the role of education in mediating the effect of parental class on individuals' social class position at labour market entry (see checked bars corresponding to left axis) is moderate overall, and tends to be smaller for lower social-class cut-offs, ranging between 27 per cent at the lowest social class cut-off to around 37 at the highest social class cut-off. ${ }^{9}$ Put differently, more than 60 per cent of the parental class effect does not go through individuals' education, even when contrasting attainment in the salariat with attainment in lower classes. These results are in line with those reported in past research (see, e.g. Breen and Karlson, 2013; Betthäuser, 2019).

But, and more importantly for our purposes, with regards to the mediating role of cognitive ability (see grey bars corresponding to left axis), we find evidence in support of the expectation that cognitive ability accounts for less of the parental class effect when individuals' 
social class position - rather than their educational attainment-is the outcome in focus. Only between 17 and 20 per cent of the total parental class effect is mediated by cognitive ability and this proportion does not differ substantially across the social class distribution. ${ }^{10}$ This also means that when limiting our attention to the part of the parental class effect that is not mediated by individuals' education, at most around 30 per cent of the attainment gap between individuals with the same level of education but coming from different class backgrounds can be accounted for by differences in cognitive ability between individuals from working class backgrounds and individuals from more advantaged positions. By contrast, we find no evidence for the expectation that locus of control mediates more of the parental class effect on individuals' labour market position, as compared to its role in mediating the parental class effect on educational attainment. As shown in Figure III (black bars corresponding to left axis), only about 3 to 5 per cent of the total association between parental class and individuals' social class position at labour market entry is mediated by individuals' locus of control. ${ }^{11}$ This is primarily due to the substantially weaker association between parental class and individuals' locus of control, compared to the association between parental class and individuals' cognitive ability - see the coefficients in M1 and M2 in Table III.

The relatively modest role of cognitive ability in mediating the parental class effect on individuals' social class position at labour market entry, gross or net of educational attainment, stands in contrast to the view that variation in cognitive ability should account for most of the differences in labour market chances of individuals from different social class backgrounds (cf. Herrnstein and Murray, 1994). However, as discussed above, it may be the case that the mediating role of cognitive ability - as well as that of locus of control and individuals' educational attainment - increases as individuals' advance in their careers and become more removed from their parental context, with factors such as parents' professional network and wealth decreasing in relevance.

To test whether this is the case, Figure IV plots the total effect of parental class on individuals social class position at the point of occupational maturity (black dots corresponding to right axis), as well as the extent to which this total effect is mediated by individuals' level of education (measured at occupational maturity), their cognitive ability and their locus of control (stacked bars corresponding to left axis). First of all, it is important to note that the total effect of individuals' parental class background on their own social class position appears to be higher at the point of occupational maturity than is the case at the point of labour market entry - i.e., parental background appears to matter more, not less, at this later stage in the life-course. We also find that educational qualifications mediate more of the total effect of parental class on individuals' class position at occupational maturity than at labour market entry. For example, around 50 per cent of the probability-difference in being found in the salariat between children of the working class and children of more advantaged classes is accounted for by the fact that the former are on average less educated, as compared to about 40 per cent at the point of labour market entry. By contrast, we do not find any evidence for the expectation that the parental class effect is increasingly mediated by either cognitive ability or locus of control as individuals progress through their careers. In other words, even at the stage of occupational maturity, only a minority-between 17 and 20 per cent_-of the difference in the social class position between individuals from different social class origins can be attributed to differences in their cognitive ability and even less-between 3 and 5 per cent-can be explained by variation in the level of their locus of control. ${ }^{12}$ 
Figure IV. Decomposition of the total effect of parental class on individuals' social class attainment at occupational maturity

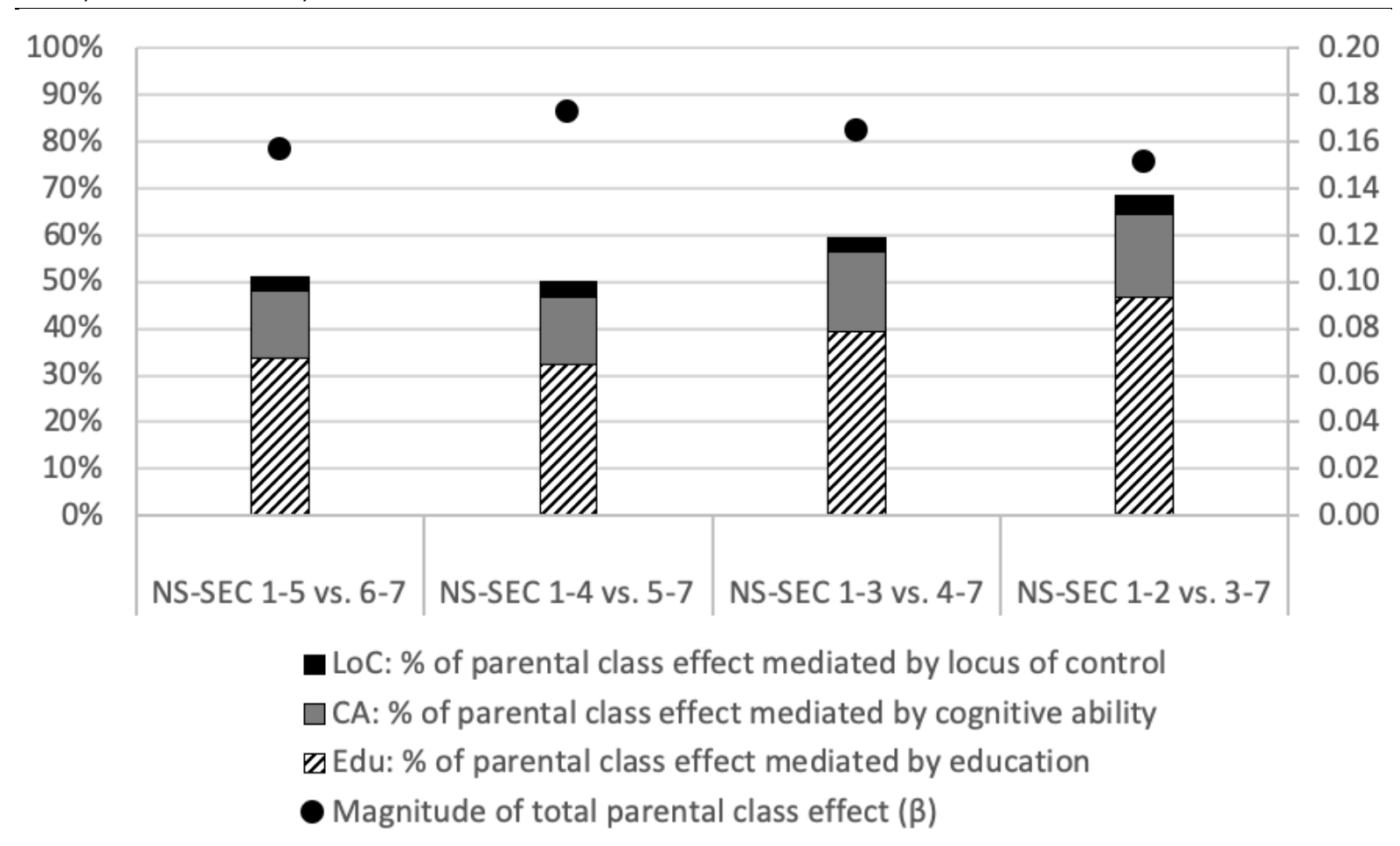

Notes: The total effect of parental class is marked by the black dots, which correspond to the right axis ( $95 \% \mathrm{Cls})$. The per centage of the total effect that is mediated by educational attainment, cognitive ability and locus of control is marked by the stacked bars, which correspond to the left axis.

\section{Conclusion}

In their controversial volume, The Bell Curve, Herrnstein and Murray (1994) claim that educational and labour market inequalities between people from different social class backgrounds are mainly due to differences in cognitive ability between them. More than two decades later this view is still influential in both academic and policy circles (see, e.g. Marks, 2014; Cummings, 2013; Murray, 2012; Saunders, 2012).

The first aim of this article has been to empirically test the arguments advanced in The Bell Curve and more recent iterations thereof by examining the extent to which differences in cognitive ability can explain educational and labour market inequalities between individuals from workingclass backgrounds and individuals from higher social class backgrounds. We find that, contrary to the claims made by these authors, cognitive ability only mediates about 35 per cent of the parental class effect on individuals' educational attainment. This finding is consistent with the existing literature that has identified a substantial 'direct' effect of parental class on individuals' educational attainment, net of cognitive ability (Bourne et al., 2017; Bukodi et al., 2017, Erikson, 2016; Mood et al., 2012; Hsin and Xie, 2016)

While much of the existing literature in this area has focused on individuals' educational attainment as the main outcome of interest, our article also considers the proportion of the parental class effect on individuals' social class position that is mediated by cognitive ability at different points in their labour market careers. As expected, when we consider the proportion of the parental class effect on individuals' social class position at labour market entry, we find that 
cognitive ability mediates even less of the parental class effect than is the case for individuals' educational outcomes. More specifically, we find that less than 20 per cent of the total association between parental class and individuals' social class position at labour market entry is mediated by cognitive ability. Whilst one may expect these per centages to increase as individuals progress in their labour market careers and become more removed from their parental contexts, this is not the case: the mediation per centages remain remarkably stable across individuals' working lives.

While our findings confirm that differences in cognitive ability play some role in explaining the inequality in labour market chances between individuals from working-class backgrounds and individuals from more advantaged backgrounds, their mediating role is much more limited than has been suggested by Herrnstein and Murray (1994) and others. In short, we find no evidence in support of the claim that the tendency of individuals from working-class backgrounds to obtain lower social class positions than individuals from higher social class backgrounds is primarily due to the former being, on average, less intelligent than the latter.

Our findings also pose a direct challenge to Cumming's report (2013: 74) in which he effectively questions the importance of lowering the effect of children's social background on their educational attainment as a political priority. We see this view as unwarranted on two accounts. First, our results show that working-class children in Britain are at a distinct disadvantage in terms of their cognitive development, even before they begin lower secondary education. Given the existing evidence on the crucial role of environmental factors on children's cognitive development (see, e.g. Cunha and Heckman 2007; Heckman, 2007), we see a clear need for policies to decrease educational inequalities by equalising the conditions for the cognitive development of children from different social class backgrounds. In particular, interventions during pregnancy and the first years of life, such as the 'A Better Start' programme that is currently being implemented across different sites in Britain, may be an effective means to this end (see Barlow, 2015). Second, our finding that a substantial part of the inequality in educational and labour market attainment between people from working-class backgrounds and people from more advantaged backgrounds is not in fact accounted for by cross-class differences in cognitive ability shows that there is a need for researchers and policy makers to identify and address the channels through which individuals' parental class background shapes their life chances, above and beyond its effects on individuals' cognitive development.

An important question that follows from our finding on the limited mediating role of cognitive ability is what other individual-level characteristics may play a role in channelling the intergenerational transmission of inequality. Building on the growing literature on the importance of non-cognitive attributes for individuals' life chances, the second aim of our article was to examine whether and to what extent people's sense of control over their lives-their locus of control-mediates the effect of growing up in a working-class family on individuals' educational attainment and social class position, and how this mediating role compares to that of cognitive ability. We find that locus of control does indeed play a role in mediating the parental class effect, but one that is substantially smaller than that of cognitive ability. More specifically, our results indicate that locus of control mediates only about 4 per cent of the association between parental class and individuals' educational attainment and between 3 to 5 per cent of the total association between parental class and individuals' social class position. As is the case for cognitive ability, we find that the mediating role of locus of control remains stable across individuals' working lives.

One limitation of our study is that we are unable to gauge to what extent the relatively low level of locus of control of children from working-class backgrounds reflects a reasonable estimate 
by these children of the level of control they truly have over their lives. Many working-class children will learn, observing the obstacles faced by their parents and other family members, that their chances for upward mobility are constrained. In particular those living in areas of high poverty and unemployment might be right to believe that their fate is somewhat out of their control. This low sense of control is likely to reinforce the educational and labour market disadvantage of individuals from working-class backgrounds and may thus become a self-fulfilling prophecy.

We would like to stress that the modest role of locus of control that we have found in mediating the parental class effect on individuals educational and labour market outcomes does not imply that policies that serve to strengthen the sense of control amongst disadvantaged children will be ineffective. To the contrary, the existing evidence on the importance of individuals' locus of control for a range of more specific labour market outcomes suggests that policies that successfully instil a greater sense of control amongst disadvantaged children may aid them in their educational and labour market careers and thus compensate for some of the disadvantages they face (see Ng-Knight and Schoon, 2017). However, we believe that the most effective means to increase the sense of control and the life chances of children from working-class backgrounds could be the provision of high-quality job opportunities, particularly in the country's 'mobility cold-spots' (Social Mobility Commission, 2016) and vocational training programmes designed to equip young people from disadvantaged backgrounds with the necessary skillset to enter these jobs.

Acknowledgements: The authors are grateful to the Centre for Longitudinal Studies (CLS), UCL Institute of Education, for the use of the BCS70 Data and to the UK Data Service for making them available. Neither CLS nor the UK Data Service bear any responsibility for the analysis or interpretation of these data. The authors would like to express their gratitude to Anette Fasang, Brian Nolan, John H Goldthorpe, the participants of the Social Inequality Research Group at the University of Oxford, as well as the editors and the anonymous reviewers at the British Journal of Sociology for their comments on earlier drafts of this article.

Funding: The research for this article was supported by the Economic and Social Research Council (ESRC Grant ES/J500112/1) and the Nuffield Foundation (EDU/42195).

Data Availability Statement. The data that support the findings of this study are available from the UK Data Archive. Restrictions apply to the availability of these data, which were used under license for this study. Data are available at http://doi.org/10.5255/UKDA-SN-5641-2 with the permission of the UK Data Archive. 
Barlow, J. 2015 The Impact and Economic Evaluation of 'A Better Start', University of Warwick. Betthäuser, B.A. 2019 'Left behind? Over-time change in the social mobility of children from unskilled working-class backgrounds in Germany', Acta Sociologica (in press).

Betthäuser, B.A., Bourne, M. and Bukodi, E. 2019 Measuring social origin, cognitive ability and educational attainment in the 1970 British Cohort Study (BCS70). SOCED Data Note Bernardi, F. and Ballarino, G. 2016 Education, occupation and social origin, Cheltenham, UK: Edward Elgar Publishing.

Blanden, J., Gregg, P. and Macmillan, L. 2007 'Accounting for intergenerational income persistence: Noncognitive skills, ability and education', The Economic Journal 117(519): p.C43-C60. Bourne, M., Bukodi, E., Betthäuser, B.A. and Goldthorpe, J.H. 2018 "'Persistence of the social": The role of cognitive ability in mediating the effects of social origins on educational attainment in Britain', Research in social stratification and mobility. 58: p.11-21.

Breen, R. and Karlson, K.B. 2013 'Education and social mobility: New analytical approaches', European sociological review 30(1): p.107-118.

Bukodi, E. and Goldthorpe, J.H. 2011 'Class Origins, Education and Occupational Attainment in Britain', European Societies 13(3): p.347-375.

Bukodi, E. and Goldthorpe, J.H. 2013 'Decomposing "social origins": The effects of parents' class, status, and education on the educational attainment of their children', European Sociological Review 29(5): p.1024-1039.

Bukodi, E., Erikson, R. and Goldthorpe, J.H. 2014 'The effects of social origins and cognitive ability on educational attainment: Evidence from Britain and Sweden', Acta Sociologica 57(4): p.293-310.

Bukodi, E., Bourne, M. and Betthäuser, B.A. 2017 'Wastage of talent? Social origins, cognitive ability and educational attainment in Britain', Advances in Life Course Research 34: p.3442.

Bukodi, E. and Goldthorpe, J.H. 2019 Social mobility and education in Britain: research, politics, and policy, Cambridge: Cambridge University Press.

Caliendo, M., Cobb-Clark, D.A. and Uhlendorff, A. 2015 'Locus of control and job search strategies', Review of Economics and Statistics 97(1): p.88-103.

Chan, T.W. and Goldthorpe, J.H. 2004 'Is there a status order in contemporary British society?', European Sociological Review 20(5): p.383-401.

Cheng, H. and Furnham, A. 2012 'Childhood cognitive ability, education, and personality traits predict attainment in adult occupational prestige over 17years', Journal of Vocational Behavior 81(2): p.218-226.

Colom, R., Abad, F.J., Garcia, L.F. and Juan-Espinosa, M. 2002 'Education, Wechsler's full scale IQ, and G', Intelligence 30(5): p.449-462.

Cox, D.R. and Wermuth, N. 1992 'A comment on the coefficient of determination for binary responses', The American Statistician 46(1): p.1-4.

Cummings, D. 2013 Some thoughts on education and political priorities, London: UK Government, Department of Education.

Cunha, F. and Heckman, J. 2007 The technology of skill formation, National Bureau of Economic Research.

Cunha, F. and Heckman, J.J. 2009 'The economics and psychology of inequality and human development', Journal of the European Economic Association 7(2-3): p.320-364.

Deary, I.J. 2001 Intelligence: A very short introduction, OUP Oxford. 
Devlin, B. 1997 Intelligence, genes, and success: Scientists respond to 'The Bell Curve', New York: Springer.

Dunifon, R. and Duncan, G.J. 1998 'Long-run effects of motivation on labor-market success', Social Psychology Quarterly: p.33-48.

Erikson, R. 2016 'Is it enough to be bright? Parental background, cognitive ability and educational attainment', European Societies 18(2): p.117-135.

Erikson, R. and Goldthorpe, J.H. 1992 The constant flux, Oxford: Oxford University Press.

Erikson, R. and Jonsson, J.O. 1998 'Social origin as an interest-bearing asset', Acta Sociologica 41(1): p.19-36.

Erikson, R. and Torssander, J. 2008 'Social class and cause of death', European journal of public bealth 18(5): p.473-478.

Feinstein, L. 2000 The relative economic importance of academic, psychological and behavioural attributes developed on childhood, Centre for Economic Performance, LSE

Fischer, C.S., Hout, M., Jankowski, M.S., Lucas, S.R., Swidler, A. and Voss, K. 1996

Inequality by design: Cracking the bell curve myth, Princeton University Press.

Galindo-Rueda, F. and Vignoles, A. 2005 'The declining relative importance of ability in predicting educational attainment', Journal of Human Resources 40(2): p.335-353.

Gammage, P. 1975 Socialisation, schooling and locus of control. University of Bristol.

Goodman, A. and Gregg, P. 2010 Poorer children's educational attainment: How important are attitudes and behaviour?, York: Joseph Rowntree Foundation.

Gottfredson, L.S. 1985 'Education as a valid but fallible signal of worker quality’ A. C. Kerchkoff (ed), Research in sociology of education and socialization 5: p.119-165.

Gottfredson, L.S. 2003 'G, jobs and life' in H. Nyborg (ed) The scientific study of general intelligence, Elsevier.

Gregg, P., Propper, C. and Washbrook, E. 2007 'Understanding the relationship between parental income and multiple child outcomes', LSE STICERD Research Paper No. CASE129. Heckman, J.J. 2007 'The economics, technology, and neuroscience of human capability formation', Proceedings of the national Academy of Sciences 104(33): p.13250-13255.

Heckman, J.J., Stixrud, J. and Urzua, S. 2006 The effects of cognitive and noncognitive abilities on labor market outcomes and social behavior, National Bureau of Economic Research.

Hernstein, R. and Murray, C. 1994 The Bell Curve: Intelligence and class structure in American life, New York: The Free Press.

Hsin, A. and Xie, Y. 2016 'Life-course changes in the mediation of cognitive and non-cognitive skills for parental effects on children's academic achievement', Social Science Research.

Jackson, M. 2006 'Personality traits and occupational attainment', European Sociological Review 22(2): p.187-199.

Jacoby, R. and Glauberman, N. 1998 The Bell Curve Debate, New York, N.Y.: Times Books. Joshi, H. 2014 'Non-cognitive' Skills: What are they and How can they be Measured in the British Cohort Studies? A Literature Review, London: Centre for Longitudinal Studies.

Karlson, K.B., Holm, A. and Breen, R. 2012 'Comparing regression coefficients between same-sample nested models using logit and probit', Sociological Methodology 42(1): p.286-313.

Macmillan, L. 2013 The role of non-cognitive and cognitive skills, behavioural and educational outcomes in accounting for the intergenerational transmission of worklessness, IoE, University College London.

Marks, G.N. 2014 Education, social background and cognitive ability: The decline of the social, New York: Routledge. 
McGee, A.D. 2015 'How the perception of control influences unemployed job search', Industrial and Labor Relations Review 68(1): p.184-211.

Mills, M. 2019 'Genetic determinism versus genetic ignorance’, BioSocieties 14(2): p.300-319.

Mood, C. 2010 'Logistic regression: Why we cannot do what we think we can do, and what we can do about it', European sociological review 26(1): p.67-82.

Mood, C., Jonsson, J.O. and Bihagen, E. 2012 'Socioeconomic persistence across generations: Cognitive and non-cognitive processes', Chapter 3: p.53-83.

Murray, C. 2012 Coming Apart: The State of White America, 1960-2010, Crown Publishing Group.

Nelson, E. and Mathia, K.E. 1995 'The relationships among college students' locus of control, learning styles, and self prediction of grades', Education research and perspectives 22(2): p.110.

Ng-Knight, T. and Schoon, I. 2017 'Can Locus of Control Compensate for Socioeconomic Adversity in the Transition from School to Work?', Journal of Youth and Adolescence: p.1-15.

Osborn, A.F. and Milbank, J.E. 1987 The effects of early education: A report from the Child Health and Education Study, Oxford University Press, USA.

Osborne Groves, M. 2005 'Personality and the intergenerational transmission of economic status' in S. Bowles, H. Gintis, and M. Osborne Groves (eds) Unequal chances: Family background and economic success, Princeton University Press.

Pearlin, L.I. and Kohn, M.L. 1966 'Social class, occupation, and parental values', American sociological review: p.466-479.

Pennington, C. R., Heim, D., Levy, A. R., and Larkin, D. T. 2016. Twenty years of stereotype threat research: A review of psychological mediators. PloS One, 11(1).

Pfeffer, F. and Hällsten, M. 2012 'Mobility regimes and parental wealth', University of Michigan, Population Studies Center, Working Paper 12(76).

Plomin, R. 2018 Blueprint: How DNA makes us who we are, MIT Press.

Rawls, J. 1971 A theory of justice, Harvard university press.

Rose, D. and Pevalin, D.J. 2005 The National Statistics Socio-economic Classification: Origins, development and use, Palgrave Macmillan Basingstoke.

Saunders, P. 2012 Social mobility delusions: Why so much of what politicians say about social mobility is wrong, misleading or unreliable, London: Civitas.

Saunders, P. 1997 'Social Mobility in Britain: An Empirical Evaluation of Two Competing Explanations', Sociology 31(2): p.261-288.

Schoon, I. 2008 'A transgenerational model of status attainment: The potential mediating role of school motivation and education', National Institute Economic Review 205(1): p.72-82.

Social Mobility Commission 2016 State of the Nation 2016: Social Mobility in Great Britain, London: Social Mobility Commission.

Spearman, C. 1904 “'General Intelligence” Objectively Determined and Measured', The American Journal of Psychology 15(2): p.201-292.

Stumm, S. von, Gale, C.R., Batty, G.D. and Deary, I.J. 2009 'Childhood intelligence, locus of control and behaviour disturbance as determinants of intergenerational social mobility', Intelligence 37(4): p.329-340.

White, I.R., Royston, P. and Wood, A.M. 2010 'Multiple imputation using chained equations', Statistics in Medicine 30(4): p.377-399.

University of London, Institute of Education, Centre for Longitudinal Studies. 20161970 British Cohort Study Response Dataset, 1970-2012. 3rd Edition. UK Data Service. SN: 5641, http://doi.org/10.5255/UKDA-SN-5641-2 
Wolf, A. 2011 Review of vocational education: The Wolf Report, London: Stationery Office.

\footnotetext{
${ }^{1}$ We use the term 'effect' in the statistical sense of the word, since most studies referred to, as well as our own findings, do not identify causal relationships, but shed light on the patterns of association between the focal variables discussed. ${ }^{2}$ It is generally accepted that individuals' cognitive ability develops early in life and remains relatively stable thereafter. With regards to non-cognitive attributes, such as locus of control, there is some evidence that they are more malleable and develop over a longer period of time, possibly into early adulthood (Cunha and Heckman, 2009). However, since one of our aims is to draw comparisons between the mediating roles of cognitive ability and locus of control, we measure them both at the same age.

${ }^{3}$ To the extent that these tests capture children's general ability to perform well on these types of tests, and to the extent that this general ability predicts educational and labour market outcomes, our results may, if anything, somewhat over-estimate the role of cognitive ability in mediating the parental class effect on these outcomes (see Pennington et al., 2016).

${ }^{4}$ Principal components analysis is commonly used on such subtests with the aim of capturing the underlying latent construct of general intelligence (g) (see Spearman, 1904, on the theoretical background, and Schoon, 2008; Bukodi et al., 2014; and Galindo-Rueda and Vignoles, 2005 on the methodological aspects).

${ }^{5}$ We ran auxiliary analyses which show that the main empirical patterns we find hold for both women and men. We note any observed differences when discussing the results of our analyses.

${ }^{6}$ We investigated the possibility of an interaction between parental class and cognitive ability, as well as between parental class and locus of control, but found that including these interaction terms does not significantly improve the fit our analytical models.

${ }^{7}$ Table AIV presents the estimated path coefficients using the annotation provided in Figure I, alongside their standard errors, for the different outcome variables of our analysis.

${ }^{8}$ To the best of our knowledge, there is no dependable way to compute confidence intervals for mediation per centages in the path-analytical framework. We therefore focus on the empirical patterns in our results to gauge the robustness of our findings.

${ }^{9}$ The pattern is somewhat stronger for women than for men (see Figures AI and AII in the Online Appendix).

${ }^{10}$ Clearly, cognitive ability also accounts for part of the mediating role of educational attainment, given that cognitive ability mediates part of the parental class effect on educational attainment. Figure AIII in the Online Appendix shows the mediating per centages when educational attainment is not controlled for.

${ }^{11}$ When running our models separately by gender, we find that the role of locus of control in mediating the parental class effect on individuals' likelihood of obtaining a position in the salariat (as opposed to obtaining a position in a lower class) is higher for women than for men (see Figures AI and AII). This is in line with existing evidence of a greater importance of locus of control in predicting labour market outcomes, such as unemployment, for women, as compared to men (Feinstein, 2000). Aside from this difference, the empirical patterns we find with regards to the mediating role of locus of control are very similar across genders.

${ }^{12}$ As noted above, we test the robustness of our findings using the alternative decomposition method developed by Karlson and colleagues, the 'KHB method' (Karlson et. al., 2012). Since in case of multiply imputed data there are no straightforward ways to calculate individual mediating percentages when multiple mediators and confounders are involved, we compute the percentages of the associations between parental class and different outcomes that is jointly mediated by cognitive ability, locus of control and educational attainment (see Figure AIV). The results from our KHB analysis confirm the empirical patters that we observed in our main analysis.
} 